\title{
SEASONAL AND REGIONAL DIFFERENCES IN LIGHTING CONDITIONS AND THEIR INFLUENCE ON MELATONIN SECRETION
}

\author{
Krzysztof BŁażejCzyK ${ }^{1,4}$, TAKeshi Morita ${ }^{2}$, TOMOKO Ueno-TOWATARI ${ }^{2}$, \\ ANNA BŁAŻEJCZYK ${ }^{3}$, JOANNA WIECZOREK ${ }^{4}$ \\ ${ }^{1}$ Institute of Geography and Spatial Organization, Polish Academy of Sciences, Warsaw, Poland \\ ${ }^{2}$ Tomoko Ueno-Towatari, Fukuoka Woman University, Fukuoka, Japan \\ ${ }^{3}$ Bioklimatologia, Laboratory of Bioclimatology and Environmental Ergonomics, Warsaw, Poland \\ ${ }^{4}$ Faculty of Geography and Regional Studies, University of Warsaw, Poland
}

Manuscript received: April 2, 2014

Revised version: July 28, 2014

BŁażejczyK K., Morita T., Ueno-Towatari T., BŁażejCZYK A., WieczoreK J., 2014. Seasonal and regional differences in lighting conditions and their influence on melatonin secretion. Quaestiones Geographicae 33(3), Bogucki Wydawnictwo Naukowe, Poznań, pp. 17-25, 1 table, 6 figs. DOI 10.2478/quageo-2014-0026, ISSN 0137-477X.

AвstRACт: The paper presents essential results of multidisciplinary research dealing with differences in lighting conditions (natural and/or artificial) and their possible influence on melatonin secretion studied in Fukuoka (Japan) and in Warszawa (Poland). Several characteristics of lighting were considered (intensity of global 0.4-3.0 $\mu \mathrm{m}$, visible 0.40 .76 $\mu \mathrm{m}$ solar radiation, illuminance (lux), peak irradiance $\left(\mu \mathrm{W} \cdot \mathrm{cm}^{-2} \cdot \mathrm{nm}^{-1}\right)$, Color Corresponded Temperature $(\mathrm{CCT}, \mathrm{K})$ and peak wave length (nm)). Diurnal cycle of melatonin secretion was examined at volunteers (Poland - 15, Japan - 18), young male and female (21-33 years). Saliva samples were collected at $3 \mathrm{~h}$ intervals, beginning at 10:00h on Thursday with subsequent sampling times at 13:00, 16:00, 19:00, 22:00 and at 01:00, 04:00 07:00h on Friday. Melatonin concentration (MC) was measured by commercials ELISA kit tests.

KEY WORDS: visible radiation, lighting conditions, radiation climate of Poland and Japan,melatonin secretion, chronobiology

Address of the corresponding author: Krzysztof Błażejczyk, Institute of Geography and Spatial Organization, Polish Academy of Sciences, Twarda 51/55, 00-818 Warszawa, Poland; k.blaz@twarda.pan..pl

\section{Introduction}

Light is an important factor that mediates activity of the internal biological clock, which regulates many diurnal and seasonal cycles in the human organism. One of physiological processes in humans which is mostly influenced by lighting conditions is secretion of melatonin, a major hormone of pineal gland (Arendt, 2006).

The previous researches dealing with circadian rhythm of melatonin secretion have mostly taken into consideration subjects' exposition to artificial light. They point to several lighting factors which - as we present know - influence melatonin production, e.g. the intensity of light, duration of the exposition (especially to bright and dim light), the spectral distribution of light (Morita, Tokura 1998, Morita et al. 2002, Thorne et al. 2009, Wehr et al. 1995). Majority of previous experiments were conducted in high-controlled and stable conditions, with isolation of singular stimuli. It is important to examine if demands identified there occur in a real-light conditions. Nevertheless lighting exposure of individuals 
consists of both kinds of light - natural, emitted by the Sun and changing diurnally and seasonally as well and artificial, which depends on lighting habits and be quite stable during a year. Our knowledge about the impact of this mixed-conditions exposure is still insufficient (Blazejczyk et al. 2005, Maroszek et al. 2010, Ueno-Towatari et al. 2007).

Studies of Zeitzer at al. (2000) have demonstrated that melatonin suppression is light intensity depended. Moreover, the curve of melatonin phase response to light intensity is not a linear function which results in phenomenon that melatonin secretion can be suppressed by exposure to light of several hundred luxes, such as an ordinary room light. Beside that the studies demonstrate that duration of light exposure influence nocturnal melatonin suppression although with no-linear manner. It means that we could reach the same melatonin effect with long or short, intermittent light stimuli.

Previous studies of Morita et al. (2002) noticed that lighting conditions, which are changing during a daytime period, impact the melatonin rhythm. Morning light affects the moment of the activation of melatonin secretion (DLMO, dim light melatonin onset), light during a day impacts the melatonin amplitude $(\mathrm{MC}$, maximum diurnal values) and evening lighting may shift the acrophase. It was documented that bright light exposition at morning, just after awake, results in a advancing a secretion phase while the same bright light conditions at evening in delaying it. Studies of Takatsu et al. (2006) showed that bright light exposure and high amounts of energy reached by the individuals during a daytime period lasts in increased melatonin amplitude at night.

Hebert et al. (2002) noticed that the extent of night melatonin suppression due to light is also depended on prior light exposure. The greater doses of energy absorbed by the volunteer before the studied lighting treating the less melatonin suppression during examined conditions. It means that after high irradiation during a daytime period is supposed to get less melatonin suppression after evening exposure. Moreover, it was stated that longer outdoor exposition during a daytime results in less melatonin suppression at night.
All those findings clarify that melatonin course is a consequence of lightning conditions during a daytime period. It suggests that seasonal changes of lighting should result in seasonality of the melatonin rhythm. Cole et al. (1995) and Wehr et al. (1995) considered the photoperiod length and they confirmed no correlations with melatonin course. They explain this lack of seasonality by the functioning of the modern societies when people are exposed mostly to artificial light, so they experienced a long photoperiod all year round. However, further studies focused on melatonin rhythm showed its seasonality (Arendt 2006). Seasonality in mid-latitude citizens (at Chicago example) was confirmed by Burgess and Fogg (2008). There are only few studies considering patterns of human exposition to light. Researches of Thorne et al. (2009) documented that typical diurnal exposition is varying during a year. It is differentiated by the illuminance totals, totals of visible radiation as well as a contribution of it spectral ranges. Morning light maximum illuminance levels during summer season are usually twice bigger than in winter. In winter illuminance of blue light during evening hours is significantly smaller than in summer. This differences occur even in subjects which spent most of their time indoors. For this subjects Sun exposure time is maybe not the strongest light stimuli but it still exists, so affects melatonin rhythm despite of artificial light which is constant during a year.

It was reported previously that local geographical factors (depended on latitude), like a midday Sun altitude and day length in connection with climate conditions (cloudiness, solar radiation etc.) may be responsible for observed regional differences in melatonin rhythm (Błażejczyk et al. 2005, Cole et al. 1995, Maroszek et al. 2010, Ueno-Towatari et al. 2007). The main findings of these research show that geographical location has significant consequence in melatonin rhythm. In general, the lowest concentration of melatonin is observed during the daytime, while highest intensity of solar radiation is observed. However, experimental data do not confirm that winter is the season with the smallest melatonin secretion. This may suggest that melatonin peak may depend on other factors, e.g. radiation totals absorbed during the daytime or on the length of daily exposure to dim or bright light. 
The aim of the present paper is to discuss essential results of multidisciplinary research dealing with differences in lighting conditions (natural and/or artificial) and their possible influence on melatonin secretion studied in Fukuoka (Japan) and in Warszawa (Poland).

\section{Materials and method}

The research bases on field experiment carried out in Poland (Warszawa, latitude $52^{\circ} \mathrm{N}$ ) and in Japan (Fukuoka, latitude $33^{\circ} \mathrm{N}$ ). Four times a year: in spring and autumn equinox as well as in winter and summer solstice simultaneous environmental and physiological observations were carried out.

During whole experiment, several environmental parameters were registered automatically every 1 minute (outdoors): intensity of global 0.4-3.0 $\mu \mathrm{m}$ and visible $0.4-0.76 \mu \mathrm{m}$ solar radiation as well as air temperature and humidity (with the use of HOBO Micro Station). Additionally spectral characteristics of solar light: illuminance (lux), peak irradiance $\left(\mu \mathrm{W} \cdot \mathrm{cm}^{-2} \cdot \mathrm{nm}^{-1}\right)$, Color Corresponded Temperature $(\mathrm{CCT}, \mathrm{K})$, peak wave length $(\mathrm{nm})$ were measured several times a day by LightSpex device (GretagMacbeth).

Furthermore for each subject individual characteristics of light intensity (with the use of ActiWatch, Mini Mitter Comp., Inc) and totals of energy of visible radiation in 7 spectral ranges the subject was expose (using HandyLight device) were controlled.

The experimental period lasted from Monday till Friday. In every experiment diurnal cycle of melatonin secretion was examined at volunteers (Poland - 15, Japan - 18), young male and female (21-33 years). Participants were required to sleep from 23:00 until 7:00 in total darkness and to take their ordinary activity during the day. Cigarettes, coffee and alcohol were banned.

Saliva samples were collected at $3 \mathrm{~h}$ intervals, beginning at 10:00 $\mathrm{h}$ on Thursday with subsequent sampling times at 13:00, 16:00, 19:00, 22:00 and at 01:00, 04:00 07:00 h on Friday. Saliva specimens were collected using a saliva collection tubes (Buhlmann Laboratories AG Swiss). Saliva samples were frozen at $-24^{\circ} \mathrm{C}$ until the analysis. Melatonin concentration (MC) was measured by commercials ELISA kit tests (Buhlmann Laboratories AG Swiss).

In the present paper we have considered the regional patterns of several environmental factors (day length, Sun altitude at noon, income of global solar and PAR radiation, spectral characteristics of light) as well as daytime totals of time with different light intensity (dim $-<50$ lux, fair - 51-500 lux and bright - >500 lux) and daytime totals of visible radiation $(400-750 \mathrm{~nm}$ ) for which the subject were exposed. We compare lighting characteristics with diurnal cycles of melatonin and its highest night concentration (MC in pg. $\left.\mathrm{ml}^{-1}\right)$ as well as the Time Peak for MC values. The mean, maximum and minimum values of studied parameters in each season and in each location are considered. The statistical analyses were made with the use of STATGRAPHICS Plus 2.1 software package.

\section{Results}

The studied areas were significantly differentiated in environmental factors influencing lighting conditions. In all seasons Sun altitude was significantly higher in Fukuoka (Japan) then in Warszawa (Poland). The location of studied cities at various latitudes affects also in different lengths of days (photoperiod) in particular seasons. The greatest seasonal differences are observed in Warszawa. While in December the length of day is only $7 \mathrm{~h} 42 \mathrm{~min}$ then in June day lasts $16 \mathrm{~h}$ and $47 \mathrm{~min}$. In spring and autumn equinox the day length in studied cities was similar each other (about 12 hours). The last regional factors considered here was global solar radiation (Kglob - daytime totals) and density of photosynthetically active radiation (PAR - mean daytime values). Spring and autumn daytime totals of Kglob were similar in Warszawa and Fukuoka. However, their summer and winter values differed significantly. While in winter Kglob totals in Warszawa were lower in comparison to Fukuoka than summer totals of global solar radiation in Poland were higher than in southern Japan. Opposite regional patterns were found in case of PAR. In every season its values were significantly higher in Fukuoka than in Warszawa (Fig. 1). 

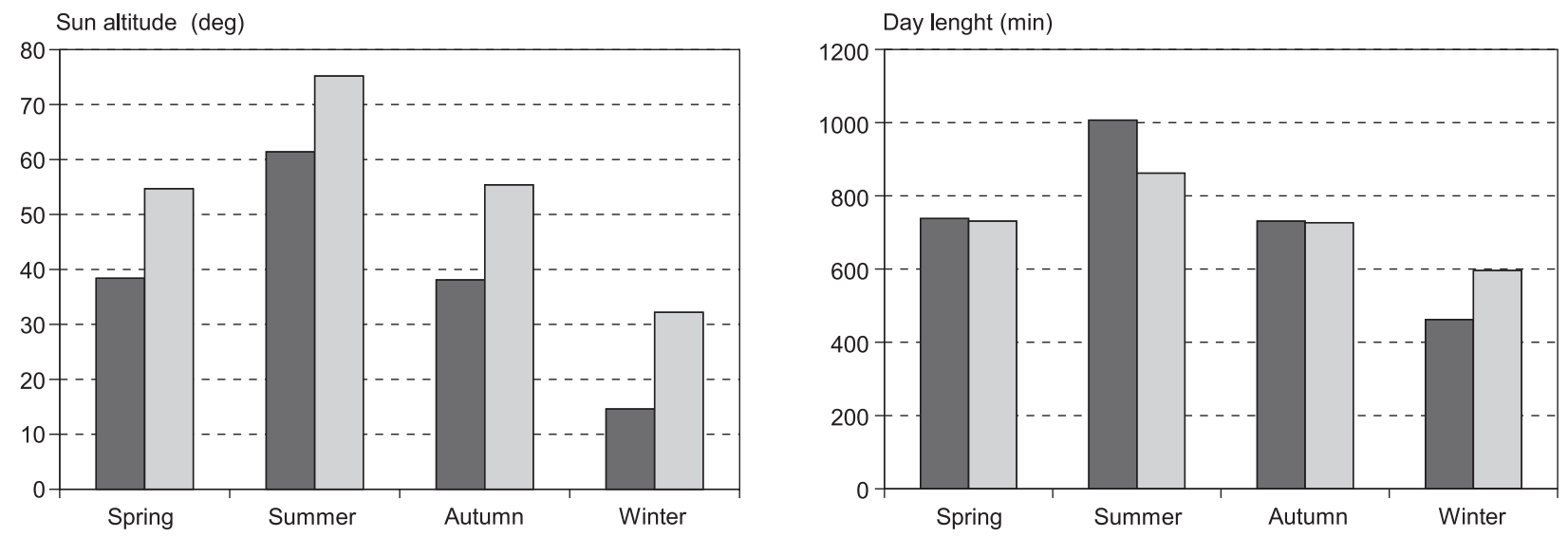

$\square$ Warszawa (Poland)

$\square$ Fukuoka (Japan)
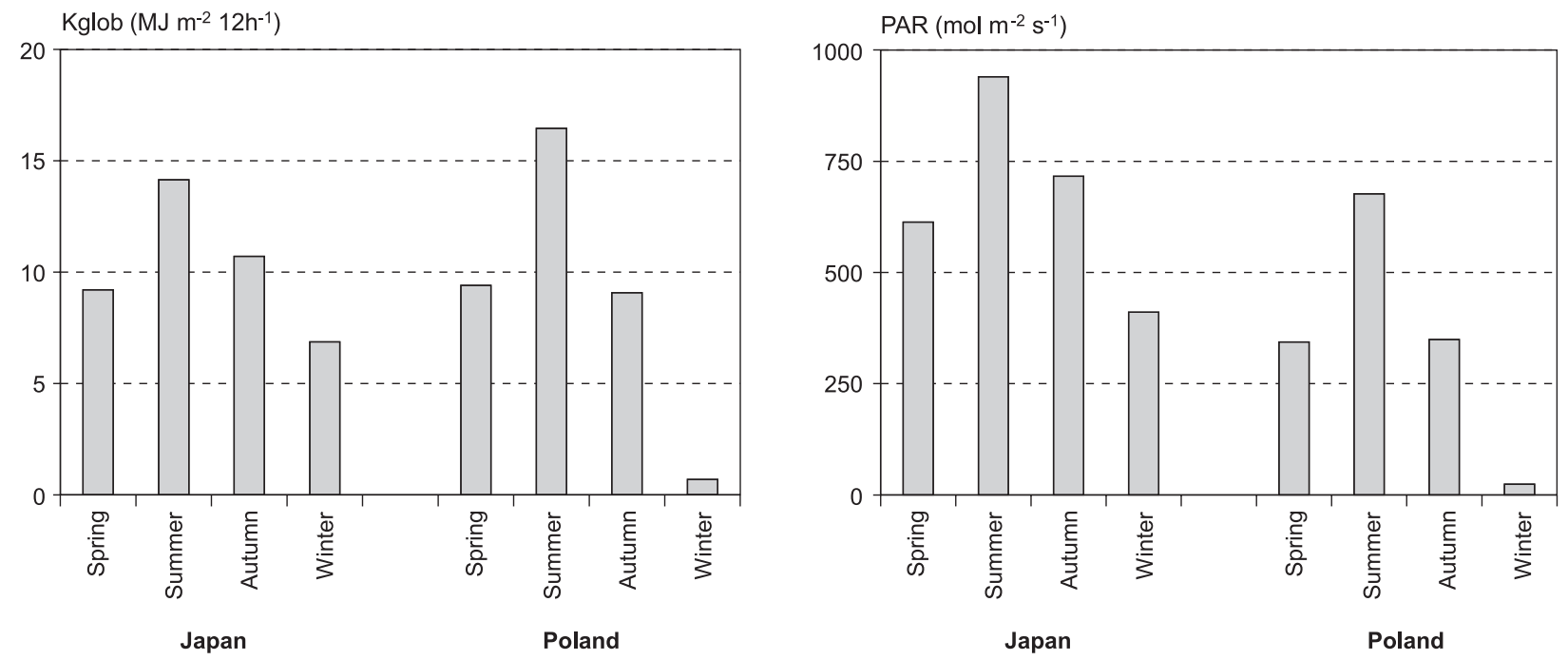

Fig. 1. Seasonal values of particular environmental parameters: day length, midday Sun altitude, daytime totals of global solar radiation $(\mathrm{Kglob})$ and mean daytime values of photosynthetically active radiation (PAR) in Fukuoka (Japan) and Warszawa (Poland)

The second group of environmental characteristics there are spectral characteristics of light. They were monitored with the use of LightSpex device. Outdoor illuminance in studied regions varied significantly. In all seasons it was higher in Japan than in Poland. The greatest differences were observed in the midday hours. While in Japan illuminance reached up to 70-80 thousands lux in spring, summer and autumn as well as 45,000 lux in winter than in Poland its maximum values only in summer reached similar level of 80,000 lux like in Japan. In spring and autumn midday illuminance reached 30-40 thousands lux. However, in winter its daily values in Poland did not exceeded 10,000 lux. Peak irradiance represents similar regional differences like illuminance and only in summer its values reached comparable values in both locations.

We have observed also great differences in peak wavelength of visible radiation and in Color Corresponded Temperature, i.e. the temperature of an ideal black body that radiates light of comparable hue to that of the light source. In spring the daily light waves have the shortest length (455 nm in Japan and $485 \mathrm{~nm}$ in Poland), which was within the range of blue light. Blue light dominated also in autumn. However, in summer and winter the observed peak wavelength was moved toward the range of green light. Almost in all seasons (except spring) CCT was significantly higher in Warszawa $(6,400-6,900 \mathrm{~K})$ than in Fukuoka (5,600-6,100 K). Thus, in Poland CCT was closer to red light than in Japan (Fig. 2). 

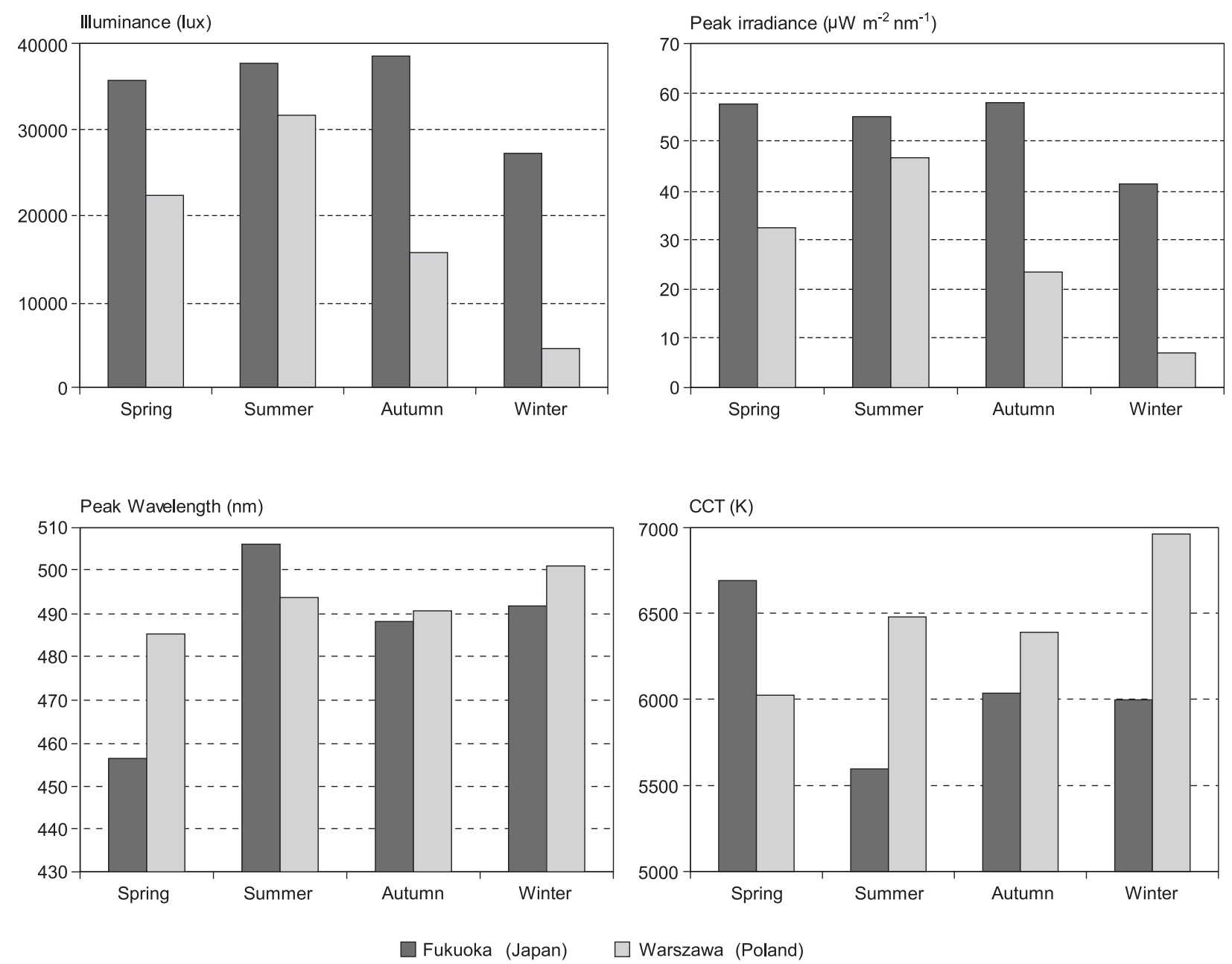

Fig. 2. Spectral characteristics of light (illuminance, peak irradiation, peak wavelength, colour corresponded temperature CCT) registered in particular seasons in studied regions

Significant differences between studied locations were observed in concentration of melatonin (MEL) at examined subjects. In both regions daily melatonin course is similar each other; it's the highest values (MC) are observed in night hours. However, MEL courses differ sea-

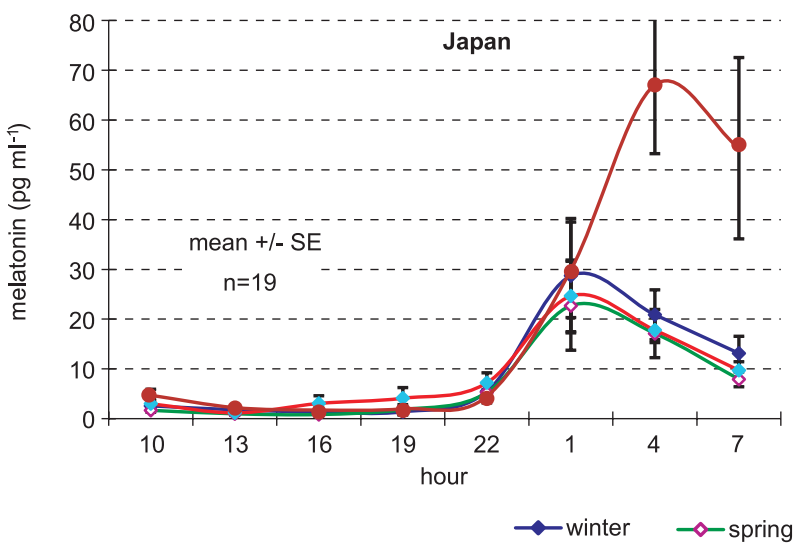

Fig. 3. Mean seasonal daily courses of melatonin concentration at Japanese and Polish subjects sonally. In general, in Poland MC values were higher than in Japan. The exceptions are: winter with very low MC in Poland and autumn, with very high $\mathrm{MC}$ in Japan (Fig. 3).

Significant differences were observed also in the time of peak values of melatonin. Within the

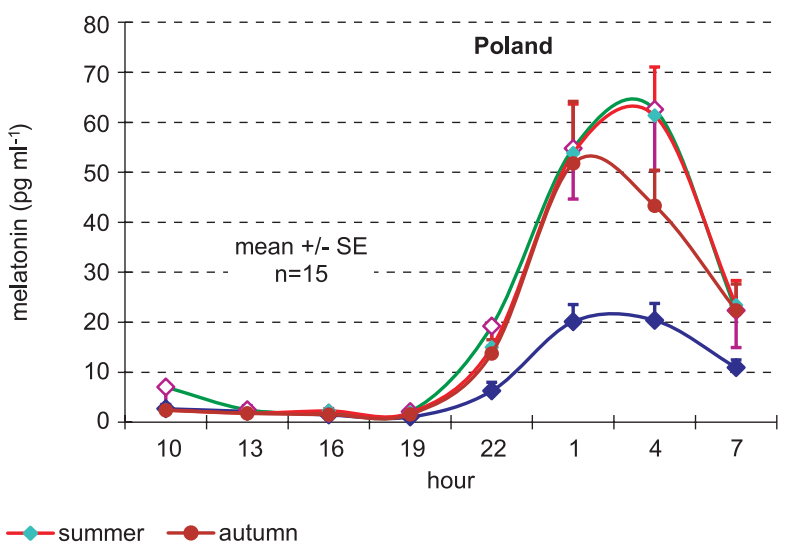


Table 1. Time of the occurrence of the highest concentration of melatonin within Polish and Japanese subjects

\begin{tabular}{|c|c|c|c|c|c|}
\hline \multicolumn{2}{|c|}{} & Spring & $\begin{array}{c}\text { Sum- } \\
\text { mer }\end{array}$ & $\begin{array}{c}\text { Au- } \\
\text { tumn }\end{array}$ & Winter \\
\hline \multirow{4}{*}{ Japan } & earliest & $1: 06$ & $1: 00$ & $0: 36$ & $1: 18$ \\
\cline { 2 - 6 } & average & $3: 36$ & $3: 06$ & $4: 24$ & $4: 30$ \\
\cline { 2 - 6 } & latest & $7: 00$ & $5: 12$ & $7: 00$ & $7: 00$ \\
\hline \multirow{4}{*}{ Poland } & earliest & $1: 06$ & $1: 06$ & $22: 00$ & $22: 54$ \\
\cline { 2 - 6 } & average & $3: 12$ & $2: 42$ & $1: 54$ & $2: 30$ \\
\cline { 2 - 6 } & latest & $5: 30$ & $4: 42$ & $5: 24$ & $4: 24$ \\
\hline
\end{tabular}

group of Polish subjects the highest concentration of melatonin occurred in all seasons earlier than at Japanese group. The greatest differences were observed in autumn and winter which are the seasons with unexpected MC values (Table 1).

The concentration of melatonin depends not only on general lighting conditions which vary regionally. Very important is also individual patterns of exposition on light characteristics. When comparing time of exposure to dim light we have noted that in Poland in all seasons it was longer than in Japan. This founding correspond with the time of exposure to fair light, which is longer in
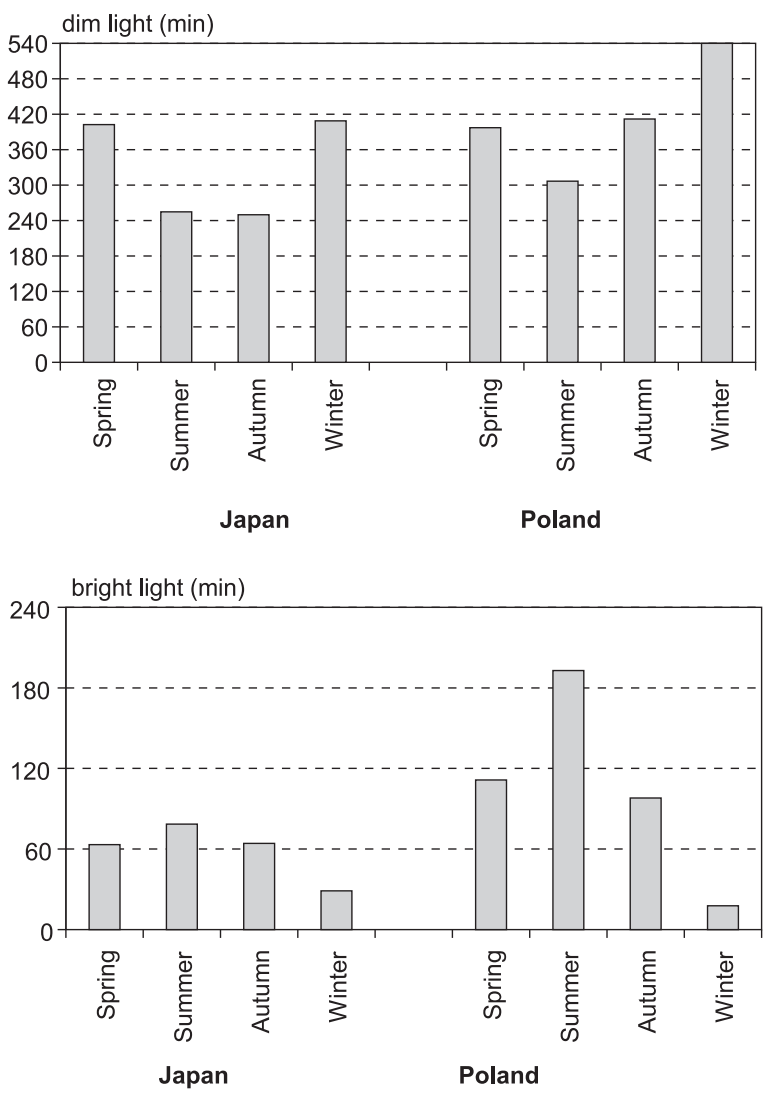

Fukuoka in comparison to Warszawa. However, time of exposure to bright light (>500 lux) was longer in Polish location. While in Japan subjects were exposed to bright light for 60-70 minutes per day during spring, summer and autumn than in Poland this time was 100-200 minutes. Only in winter bright light reached subject for no more than 30 minutes a day. The increased time of exposure to bright light in Poland corresponds with greater totals of visible radiation which reached examined subjects in Warszawa in comparison to Fukuoka (Fig. 4). It is probably caused by different day organization. In general, Polish subjects have spent more time outdoors and Japanese ones - indoor.

Comparing environmental, lighting factors and melatonin concentration in examined subjects we have found some statistically significant relationships (at $\mathrm{p}=0.05)$. In general, the relationships were better seen in Poland than in Japan. In both studied regions the concentration of melatonin (MC) observed in subjects increased due to intensity of photosynthetically active radiation
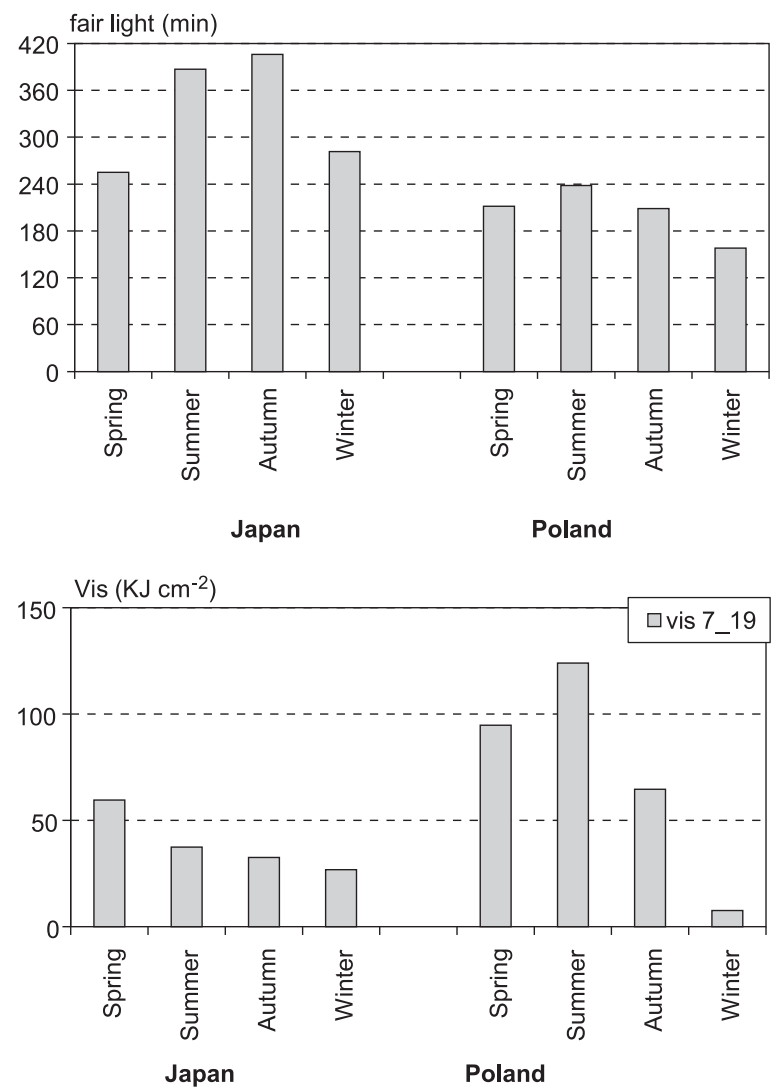

Fig. 4. Seasonal and regional differences in individual lightning characteristics the subject were exposed for: time of exposure to dim, fair and bright light and daytime totals of visible radiation 

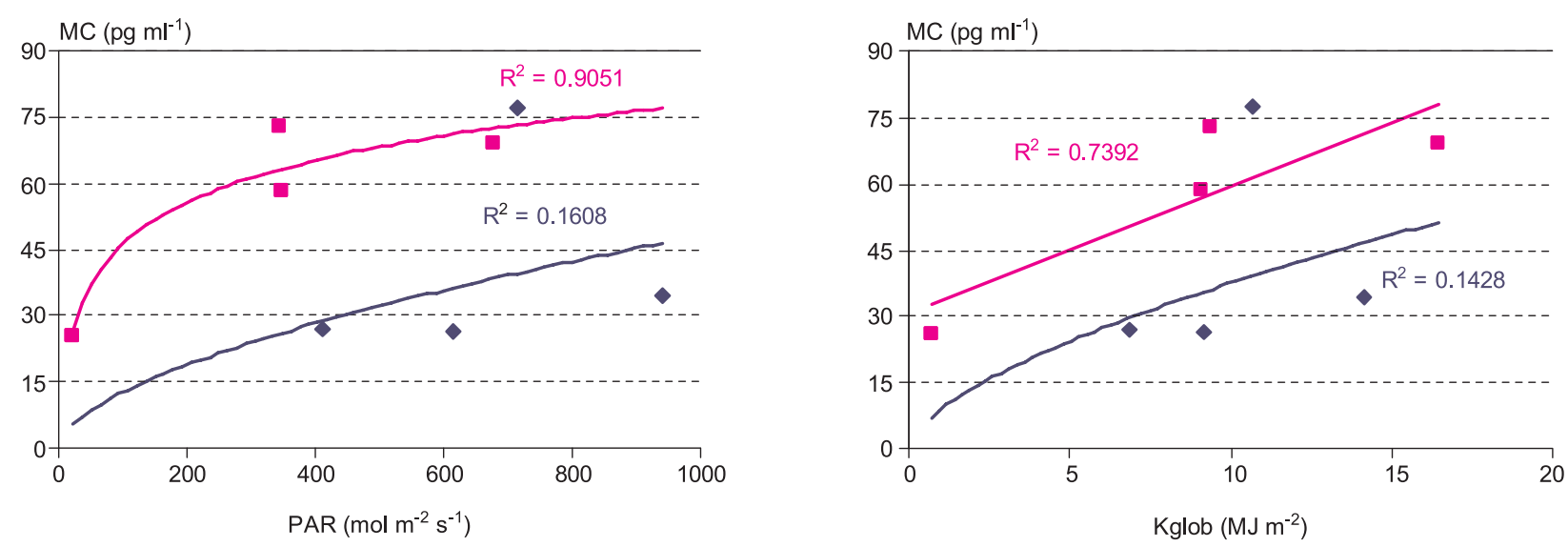

- $\mathrm{PL} \bullet \mathrm{JP}$

Fig. 5. Statistical relationships between observed day time (from 7 a.m. till 7 p.m.) characteristics of outdoor lighting conditions: average intensity of photosynthetically active radiation (PAR) and totals of global solar radiation (Kglob) and the highest night melatonin concentration (MC) at Japanese (JP) and Polish (PL) subjects
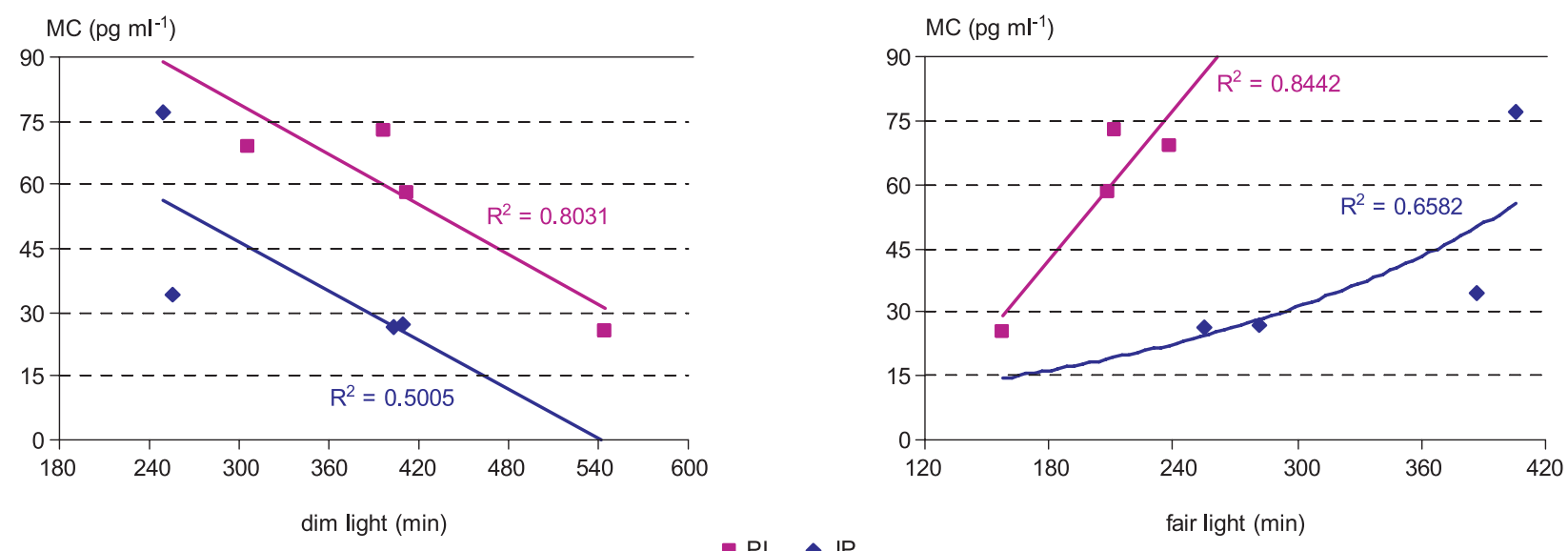

Fig. 6. Statistical relationships between observed daytime (from 7 a.m. till 7 p.m.) totals of time the subjects were exposed to dim light (<50 lux) and fair light (51-500 lux) and the highest night melatonin concentration (MC) at Japanese (JP) and Polish (PL) subjects

(PAR) and according to the increase of daily totals of global solar radiation (Kglob). The smallest MC was observed in seasons with low (Japan) or very low (Poland) values of radiation factors during day time hours. Great amount of radiation the subjects were exposed for during the day stimulated greater secretion of melatonin by pineal gland and its greater concentration in an organism (Fig. 5).

Melatonin concentration was also significantly depended on the time of exposure to dim and fair light. In general, if the time of exposure to dim light was shorter the MC was higher. On the other hand, in seasons with longer exposure to fair light the melatonin concentration was higher than in periods with short exposure time to fair light (Fig. 6).

\section{Discussion}

Each season PAR totals were significantly higher in Fukuoka than in Warszawa. Only in summer the opposite relation were found for bright light (> 500 lux). The probably explanation is that in Fukuoka during the week of experiment the cloudiness was bigger and/or subjects were engaged more into indoors activities. As was suggested in previous studies by Morita et al. (2002) it may play an additional role in affecting melatonin course. In fact it is needed to point here that the measurements of PAR were curried out in open spaces in opposite to irradiance measurements which were conducted in close surroundings of participants (device placed on a wrist). In conclusion the data of irradiations present a 
greater compliance which a actual subject's exposure, especially when subjects have spent most of the time indoors.

The time of the peak of melatonin occurred earlier in the group of Polish subjects in all seasons than at Japanese group. Analysis of the dim light $(<50$ lux $)$ exposition showed that in all the seasons the greater duration of such exposure were present within Polish group. In previous studies Morita et al (2002) has pointed that in individuals which were less exposed for light of high irradiances the melatonin peak occurred earlier. It is possible that our findings are consequence of this phenomenon. However, this should be checked in individual cases, according to the previous suggestions of Burgess and Fogg (2008) that melatonin secretion in humans presents great variation and is genetically determined.

The results of fair light exposure (51-500 lux) showed statistically significant relationships with melatonin peak. MC variability was explained by changes in the length of exposure at fair light at $84 \%$ in Poland and 65\% in Japan. As was earlier documented by Zeitzer et al. (2000) even moderate illumination may cause a significant suppression of melatonin only slight less than extremely bright light.

Exposure to bright light during daytime period enhanced nocturnal melatonin production. This effect was reported by Takatsu et al. (2006). According to the results of Hebert et al. (2002) less suppression of nocturnal melatonin is observed if conditions of bright lighting are present during the daytime. In addition, this effect is enhanced by a greater outdoors exposure. This could explain why the maximum concentration of melatonin in Poland, where longer exposure to bright light conditions during the daytime was found, were higher than in Japan.

As the researches of Morita and Tokura (1998) has shown exposure to light provided by sources which are characterized by high color temperature CCT which results in stronger suppression of melatonin than after exposure to low CCT values. It was previously discussed that in Japan high CCT fluorescent lamps are in common use. It is likely that the observed in each season (except autumn) lower MC levels and the fact that time of peak MC appeared later are a consequence of lighting in the evening. It could be good explanation especially due to consumer preferences, resulting in much higher CCT than typically used in Poland.

\section{Conclusions}

Even in populations heavily dependent on artificial lighting which is quite stable within a year the seasonal variation of the light exposure occurs. It results primarily from the impact of natural light, which nevertheless reaches the individuals. An additional role plays the pattern of subjects' activity which spent the majority of time outdoors. People taking some outdoors activities have an opportunity to enrich their exposure to very bright light, which usually did not experience in case of exposure to artificial light.

Seasonal variation of melatonin might be linked to changes in natural lighting. Thus analysis of environmental conditions, e.g. lighting intensity may be useful to verify regional differences observed in the secretion of melatonin. However, these conclusion should be confirmed in further studies.

\section{Acknowledgments}

This research was partly supported by Japan Society for the Promotion of Science grant No 16207021.

\section{References}

Arendt J., 2006. Melatonin and human rhythms. Chronobiology International 23(1-2): 21-37.

Blażejczyk K., Morita T., Kanikowska D., Tokura H., Wiktorowicz K., Ueno T., Bakowska M., 2005, Regional differences in diurnal and seasonal cycles of lighting conditions and melatonin secretion. DWD, Annalen der Meteorologie 41, 1, $17^{\text {th }}$ International Congress of Biometeorology ICB 2005: 301-304.

Burgess H.J., Fogg L.F., 2008. Individual differences in the amount and timing of salivary melatonin secretion. PLoS ONE 3(8): e3055. doi:10.1371/journal.pone.0003055.

Cole R.J., Kripke D.F., Wisbey J., Mason W.J., Gruen W., Hauri P.J., Juarez S., 1995. Seasonal variation in human illumination exposure at two different latitudes. Journal of Biological Rhythms 10(4): 324-334.

Hébert M., Martin S.K., Lee C., Eastman Ch.I., 2002. The effects of prior light history on the suppression of melatonin by light in humans. Journal of Pineal Research 33(4): 198-203. 
Maroszek J., Morita T., Błażejczyk K., 2010. Melatonin secretion in various climate zones. In: Proceedings of the 7th Conference on Biometeorology, Alberts-Ludwigs-University of Freiburg, Germany, 12-14 April 2010. Eds. Andreas Matzarakis, Helmut Mayer, Frank-M. Chmielewski. Freiburg: Meteorologischen Institut der Albert-Ludwigs-Univeristaet, 2010, Berichte des Meteorologischen Institut der Albert-Ludwigs-Univeristaet Freiburg 20: 273-277.

Morita T., Koikawa R., Ono K., Terada Y., Hyun K., Tokura H., 2002. Influence of the amount of light recived during the day and night on the circadian rhythm of melatonin secretion in woman living diurnally. Biological Rhythm Research 33(3): 271-277.

Morita T., Tokura H., 1998. The influence of different wavelengths of light on human biological rhythms. Applied Human Science 17(3): 91-96.

Ueno-Towatari T., Norimatsu K., Blazejczyk K., Tokura H., Morita T., 2007. Seasonal variations of melatonin secretion In young females under natural and artificial Light conditions In Fukuoka, Japan. Journal of Physiological Anthropology 26(2): 209-215.

Takasu N.N., Hashimoto S., Yamanaka Y., Tanahashi Y., Yamazaki A., Honma S., Honma K., 2006. Repeated exposures to daytime bright light increase nocturnal melatonin rise and maintain circadian phase in young subjects under fixed sleep Schedule. American Journal of Physiology Regulatory Integrative and Comparative Physiology 291(6): R1799-R1807.

Thorne H.C., Jones K.H., Peters S.P., Archer S.N., Dijk D-J., 2009. Daily and seasonal variation in the spectral composition of light exposure in humans. Chronobiology International 26(5): 854-866.

Wehr T.A., Giesen H.A., Moul D.E., Turner E.H., Schwarz P.J., 1995. Suppression of men's responses to seasonal changes in day length by modern artificial lighting. American Journal of Physiology 269(1 Pt 2): 173-178.

Zeitzer J.M., Dijk D-J., Kronauer R.E., Brown E.N., Czeisler Ch.A., 2000. Sensitivity of the human circadian pacemaker to nocturnal light: melatonin phase resetting and suppression. The Journal of Physiology 526(3): 695-702. 